This document is the accepted manuscript version of a published work that appeared in final form after peer review and technical editing by the publisher. To access the final edited and published work see link to "View at Publisher (DOI)" at the DORA Empa web page (https://www.dora.lib4ri.ch/empa/).

This document is confidential and is proprietary to the American Chemical Society and its authors. Do not copy or disclose without written permission. If you have received this item in error, notify the sender and delete all copies.

\title{
Abatement of polychoro-1,3-butadienes in aqueous solution by ozone, UV-photolysis, and advanced oxidation processes (03/H2O2 and UV/H2O2)
}

\begin{tabular}{|r|l|}
\hline Journal: & Environmental Science \& Technology \\
\hline Manuscript ID & es-2016-04506d.R1 \\
\hline Manuscript Type: & Article \\
\hline Date Submitted by the Author: & $18-$ Nov-2016 \\
\hline Complete List of Authors: & $\begin{array}{l}\text { Lee, Minju; École polytechnique fédérale de Lausanne, School of } \\
\text { Architecture, Civil and Environmental Engineering } \\
\text { Merle, Tony; Eawag, Water Resources \& Drinking Water } \\
\text { Rentsch, Daniel; Empa, Functional Polymers } \\
\text { Canonica, Silvio; Eawag, Swiss Federal Institute of Aquatic Science and } \\
\text { Technology (Eawag), Water Resources and Drinking Water Dept. } \\
\text { von Gunten, Urs; EAWAG, Water Resources and Drinking Water }\end{array}$ \\
\hline
\end{tabular}

\section{SCHOLARONE \\ Manuscripts}


2 Abatement of polychoro-1,3-butadienes in aqueous solution by ozone, UV-photolysis, and advanced oxidation processes

$8{ }^{\dagger}$ School of Architecture, Civil and Environmental Engineering (ENAC), École Polytechnique

$9 \quad$ Fédérale de Lausanne (EPFL), 1015, Lausanne, Switzerland

*Eawag, Swiss Federal Institute of Aquatic Science and Technology, Ueberlandstrasse 133,

118600 Duebendorf, Switzerland

${ }^{\S}$ EMPA, Swiss Federal Laboratories for Materials Science and Technology, 8600 Dübendorf,

\section{Switzerland}


20 Table of Contents (TOC) Art

Chlorobutadienes(CBDs)

-contaminated water

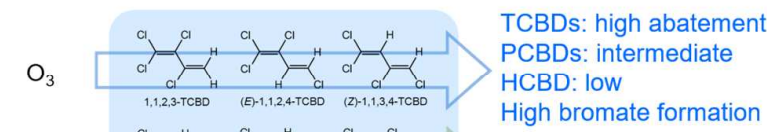

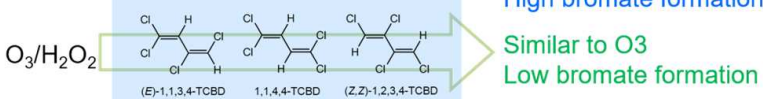

UV \& $\quad a^{a}==^{a}{ }^{a}=b^{a l} a^{a} a^{a} \quad$ Efficient direct phototransformation

$\begin{array}{lll}\mathrm{UV} / \mathrm{H}_{2} \mathrm{O}_{2} & \mathrm{a}_{\mathrm{a}}\end{array}$

$\mathrm{Br}$

No bromate formation

21 


\section{Abstract}

The abatement of 9 polychloro-1,3-butadienes (CBDs) in aqueous solution by ozone, UV$\mathrm{C}(254 \mathrm{~nm})$ photolysis, and the corresponding advanced oxidation processes (AOPs) (i.e., $\mathrm{O}_{3} / \mathrm{H}_{2} \mathrm{O}_{2}$ and $\mathrm{UV} / \mathrm{H}_{2} \mathrm{O}_{2}$ ) was investigated. The following parameters were determined for 9 CBDs: Second-order rate constants for the reactions of CBDs with ozone $\left(k_{03}\right)(<0.1-$ $\left.7.9 \times 10^{3} \mathrm{M}^{-1} \mathrm{~s}^{-1}\right)$ or with hydroxyl radicals $(k \cdot \mathrm{OH})\left(0.9 \times 10^{9}-6.5 \times 10^{9} \mathrm{M}^{-1} \mathrm{~s}^{-1}\right)$, photon fluencebased rate constants $\left(k^{\prime}\right)\left(210-2730 \mathrm{~m}^{2}\right.$ einstein $\left.{ }^{-1}\right)$, and quantum yields $(\Phi)(0.03-0.95 \mathrm{~mol}$ einstein $^{-1}$ ). During ozonation of CBDs in a natural groundwater, appreciable abatements $(>50 \%$ at specific ozone doses of $0.5 \mathrm{gO}_{3} / \mathrm{gDOC}$ to $\sim 100 \%$ at $\geq 1.0 \mathrm{gO}_{3} / \mathrm{gDOC}$ ) were achieved for tetra-CBDs followed by (Z)-1,1,2,3,4-penta-CBD and hexa-CBD. This is consistent with the magnitude of the determined $k_{\mathrm{O} 3}$ and $k_{\cdot \mathrm{OH}}$. The formation of bromate, a potentially carcinogenic ozonation by-product, could be significantly reduced by addition of $\mathrm{H}_{2} \mathrm{O}_{2}$. For a typical UV disinfection dose $\left(400 \mathrm{~J} / \mathrm{m}^{2}\right)$, various extents of phototransformations (10-90\%) could be achieved. However, the efficient formation of photoisomers from CBDs with $E / Z$ configuration must be taken into account because of their potential residual toxicity. Under UV$\mathrm{C}(254 \mathrm{~nm})$ photolysis conditions, no significant effect of $\mathrm{H}_{2} \mathrm{O}_{2}$ addition on CBDs abatement was observed due to an efficient direct phototransformation of CBDs.

KEYWORDS chlorobutadienes, groundwater, ozonation, UV photolysis, hydrogen peroxide, second-order rate constants, photon fluence-based rate constants, quantum yield, quantum chemical calculation, photoisomerization 


\section{Introduction}

Poly-chloro-1,3-butadiene (CBD) congeners (i.e., tetra-, penta-, hexa-CBD) have been detected over the last four decades in river water, ${ }^{1-5}$ groundwater, ${ }^{6-8}$ and wastewater ${ }^{4,9}$ worldwide in the concentration range of tens of $n g / L$ to a few $\mu \mathrm{g} / \mathrm{L}$. Among CBDs, hexa-chloro1,3-butadiene (HCBD) has various industrial applications such as an intermediate in manufacturing rubber compounds, as a solvent, as a fumigant, etc. ${ }^{10}$ Moreover, HCBD is inadvertently produced as a by-product from the manufacturing of chlorinated hydrocarbons such as trichloroethene (TCE) and tetrachloroethene (PCE). ${ }^{10}$ Due to the potential hazardous impacts on humans and aquatic organisms, ${ }^{10-12} \mathrm{HCBD}$ has been subject to environmental guidelines worldwide: $0.6 \mu \mathrm{g} / \mathrm{L}$ for drinking water by World Health Organization ${ }^{11}$ and an environmental quality standard value of $0.1 \mu \mathrm{g} / \mathrm{L}$ for inland surface water by the European Commission have been set. ${ }^{13-15}$ In contrast, little attention was drawn to other CBDs such as pentachloro1,3-butadienes (PCBDs) and tetrachloro-1,3-butadienes (TCBDs). ${ }^{1,6-8}$ Such CBDs are known to be formed from reductive microbial dechlorination of HCBD under anaerobic conditions. ${ }^{16,17}$ Dechlorinated products are not necessarily less harmful, e.g., vinyl chloride, which is carcinogenic, ${ }^{18}$ is produced from the reductive dechlorination of PCE and TCE. ${ }^{19}$ Therefore, the ecotoxicological impact of other CBDs than HCBD should not be overlooked. A positive clastogenic activity was recently reported for 3 TCBDs and 2 PCBDs and a target value of $75 \mathrm{ng} / \mathrm{L}$ as the sum of TCBDs and PCBDs was proposed for drinking water using the threshold of toxicological concern (TTC) concept. $^{8}$

Physical treatment technologies such as activated carbon and air stripping are commonly applied for eliminating highly chlorinated butadienes due to high hydrophobicity and volatility (e.g., $\log K_{\mathrm{ow}}=4.78^{20}$ and Henry's Law Constant $=15.3 \times 10^{-3}$ atm $\mathrm{m}^{3} / \mathrm{mol}$ at $25^{\circ} \mathrm{C}^{21}$ for HCBD). Alternatively, other treatment techniques such as ozonation, UV photolysis, or their 
combination with $\mathrm{H}_{2} \mathrm{O}_{2}$, i.e., $\mathrm{O}_{3} / \mathrm{H}_{2} \mathrm{O}_{2}$ or $\mathrm{UV} / \mathrm{H}_{2} \mathrm{O}_{2}$, also known as advanced oxidation processes (AOPs), can be potentially considered. AOPs are chemical treatment processes in which hydroxyl radicals $\left({ }^{\circ} \mathrm{OH}\right)$ are produced in situ. ${ }^{22}$ However, the current lack of information on key parameters for such treatment options hampers the assessment of the abatement efficiency for CBDs, namely, second-order rate constants for the reaction of CBDs with ozone $\left(k_{\mathrm{OO}}\right)$ or hydroxyl radicals $\left(k_{\cdot \mathrm{OH}}\right)$ for ozonation, $\mathrm{O}_{3} / \mathrm{H}_{2} \mathrm{O}_{2}$, and $\mathrm{UV} / \mathrm{H}_{2} \mathrm{O}_{2}{ }^{23,24}$ and a photon fluence-based pseudo first-order rate constant $\left(k^{\prime}\right)$ for UV-based processes such as UV photolysis or $\mathrm{UV} / \mathrm{H}_{2} \mathrm{O}_{2},{ }^{25,26}$ respectively.

In the present study, $k_{\mathrm{O} 3}, k_{\bullet \mathrm{OH}}$, and $k^{\prime}$ for UV photolysis at $254 \mathrm{~nm}$ were experimentally determined for 9 CBDs, i.e., 6 TCBD isomers $(1,1,2,3-,(E)-1,1,2,4-,(Z)-1,1,3,4-,(E)-1,1,3,4-$, $1,1,4,4-$, and $(Z, Z)-1,2,3,4-), 2$ PCBD isomers ((Z)-1,1,2,3,4- and 1,1,2,4,4-), and HCBD (Figure 1). Moreover, a previously developed quantum chemical $\operatorname{model}^{27}$ was applied to predict $k_{03}$-values for $9 \mathrm{CBDs}$, which were then compared to the experimental $k_{03}$-values. Finally, the treatment efficacy for the selected CBDs by ozonation, direct UV photolysis, and the AOPs $\mathrm{O}_{3} / \mathrm{H}_{2} \mathrm{O}_{2}$ and $\mathrm{UV} / \mathrm{H}_{2} \mathrm{O}_{2}$ was evaluated in a natural groundwater matrix. For ozonation and $\mathrm{O}_{3} / \mathrm{H}_{2} \mathrm{O}_{2}$, the abatement of other common micropollutants and bromate formation was also evaluated.

\section{Materials and methods}

\section{Standards and reagents}

All chemicals used are summarized in Text S1 in the Supporting Information.

\section{Analytical methods}


9 CBDs, $p$-chlorobenzoic acid ( $p \mathrm{CBA}$ ), atrazine, 5 micropollutants (benzotriazole, carbamazepine, diatrizoate, iopamidol, and tramadol), bromate, ozone, and $\mathrm{H}_{2} \mathrm{O}_{2}$ were quantified using appropriate analytical methods (Text S2).

\section{Determination of second-order rate constants for the reactions of CBDs with ozone $\left(k_{\mathrm{O} 3}\right)$ and hydroxyl radicals $(k \cdot \mathrm{OH})$}

$k_{\mathrm{O} 3}$ for CBDs was determined by simultaneously measuring the abatement of CBDs and the ozone decay using Eq. S1 in Text S3. Determination of $k_{\bullet \mathrm{OH}}$ for CBDs was performed by competition kinetics (Eqs. S2-S4) using $p \mathrm{CBA}$ as a competitor. ${ }^{\circ} \mathrm{OH}$ were produced by photolysis of $\mathrm{H}_{2} \mathrm{O}_{2}$. More details about analytical instruments and experimental procedures are provided in Text $\mathrm{S} 3$.

\section{Determination of photon fluence-based first-order rate constants $\left(k^{\prime}\right)$, molar absorption} coefficients $(\varepsilon)$, and quantum yields ( $\Phi)$ for phototransformation of CBDs at UV $254 \mathbf{n m}$

$k^{\prime}\left(\mathrm{m}^{2}\right.$ einstein $\left.^{-1}\right)$ for 9 CBDs for UV irradiation at $254 \mathrm{~nm}$ were determined according to Eq. 1.

$$
k^{\prime}=\frac{k_{\mathrm{CBD}, 254 \mathrm{~nm}}}{E_{p}{ }^{0}}=\frac{2.303 \Phi_{\mathrm{ATZ}, 254 \mathrm{~nm}} \varepsilon_{\mathrm{ATZ}, 254 \mathrm{~nm}} k_{\mathrm{CBD}, 254 \mathrm{~nm}}}{k_{\mathrm{ATZ}, 254 \mathrm{~nm}}}
$$

$k_{\mathrm{CBD}, 254 \mathrm{~nm}}$ and $k_{\mathrm{ATZ}, 254 \mathrm{~nm}}\left(\mathrm{~s}^{-1}\right)$ are a time-based pseudo first-order rate constant $\left(\mathrm{s}^{-1}\right)$ for the phototransformation of a CBD and atrazine at $254 \mathrm{~nm}$, respectively, $E_{\mathrm{p}}{ }^{0}$ is a photon fluence rate (einstein $\mathrm{m}^{-2} \mathrm{~s}^{-1}$ ) derived based on actinometry using atrazine (ATZ), ${ }^{26}$ and $\varepsilon_{\mathrm{ATZ}, 254 \mathrm{~nm}}$ and $\Phi_{\mathrm{ATZ}, 254 \mathrm{~nm}}$ are $386 \mathrm{~m}^{2} \mathrm{~mol}^{-1}$ and $0.046 \mathrm{~mol} \mathrm{einstein}^{-1}$ for atrazine at $254 \mathrm{~nm}$, respectively. ${ }^{26}$ Direct UV photolysis to obtain $k_{\mathrm{CBD}, 254 \mathrm{~nm}}$ was measured using the same photoreactor used for the $k_{\bullet} \mathrm{OH}$ determination (Text S3), but employing a low pressure (LP) mercury lamp (model TNN 15/32, Heraus Noblelight, Hanau, Germany) emitting monochromatic UV light at 254 
$\mathrm{nm}$ and a quartz cooling jacket. Sample solutions containing individual CBDs (1.0-3.5 $\mu \mathrm{M}$, $\mathrm{pH} 7,5 \mathrm{mM}$ phosphate buffer) prepared in quartz tubes were subject to UV irradiation. $5 \mu \mathrm{M}$ of an atrazine solution at $\mathrm{pH} 7$ (5 mM phosphate buffer) separately prepared was irradiated simultaneously to obtain the corresponding $k_{\mathrm{ATZ}, 254 \mathrm{~nm}} \cdot \varepsilon_{\mathrm{CBD}, 254 \mathrm{~nm}}$ for the 9 CBDs were determined based on the Beer-Lambert law by monitoring the absorbance at $254 \mathrm{~nm}$ using a quartz cuvette $(l=10 \mathrm{~cm})$ for various concentrations of CBDs $(0.3-6 \mu \mathrm{M}) . \Phi_{\mathrm{CBD}, 254 \mathrm{~nm}}$ was calculated according to Eq. $2 .^{25}$

$$
\Phi_{\mathrm{CBD}, 254 \mathrm{~nm}}=k^{\prime} /\left(2.303 \varepsilon_{\mathrm{CBD}, 254 \mathrm{~nm}}\right)
$$

\section{Ozonation, direct UV photolysis $(254 \mathrm{~nm})$, and advanced oxidation processes of the se-} lected CBDs and micropollutants in a natural groundwater

A natural groundwater was sampled from the Hardwald site (Latitude $47^{\circ} 32^{\prime} \mathrm{N}$ and Longitude $\left.7^{\circ} 37^{\prime} \mathrm{E}\right)$ in Switzerland $\left(\mathrm{pH}=7.95-8.05, \mathrm{DOC}=0.5 \mathrm{mgC} / \mathrm{L}\right.$, alkalinity as $\mathrm{HCO}_{3}{ }^{-}=$ $2.84 \mathrm{mM}$, and bromide $=48 \mu \mathrm{g} / \mathrm{L}$ ). For ozonation, the groundwater was spiked with a mixture of the selected CBDs $((E)-1,1,2,4-,(E)-1,1,3,4-,(Z)-1,1,3,4-, 1,1,4,4-$, and $(Z, Z)-1,2,3,4-$ TCBDs, (Z)-1,1,2,3,4-PCBD, and HCBD, 5 - $9 \mu \mathrm{g} / \mathrm{L}$ ) and 5 micropollutants (benzotriazole, carbamazepine, diatrizoate, iopamidol, tramadol, $2 \mu \mathrm{g} / \mathrm{L}$ each). Varying ozone doses $(0.25$, $0.5,1,2$, and $4 \mathrm{mg} / \mathrm{L}$ ) were investigated in the absence and presence of $\mathrm{H}_{2} \mathrm{O}_{2}$ with ratios $\mathrm{O}_{3}: \mathrm{H}_{2} \mathrm{O}_{2}(\mathrm{w} / \mathrm{w})$ of $0.5,1$, and 2. UV photolysis for the selected CBDs was carried out in the absence and presence of $\mathrm{H}_{2} \mathrm{O}_{2}(0,2.5$, and $5.0 \mathrm{mg} / \mathrm{L})$ up to a UV dose of $8600 \mathrm{~J} / \mathrm{m}^{2}$. Light screening by groundwater matrix components, estimated as a light attenuation factor as described elsewhere, ${ }^{28}$ was negligible $(<2 \%)$. Therefore, no light screening correction for the UV dose was applied.

\section{Quantum chemical computations for the prediction of $k_{03}$ of CBDs}


137 Quantum chemical computations were conducted using Gaussian 09 (Revision C.01). ${ }^{29} A b$ initio Hartree-Fock (HF) and the Density Functional Theory (DFT)-B3LYP method with the $6-311++\mathrm{G}^{* *}$ basis set were used. The integral equation formalism polarizable continuum model (IEF-PCM) ${ }^{30}$ was used for all the computations to account for the solvent effect applying a dielectric constant of 78.3 for water. Natural bond orbital (NBO) analyses were conducted using the NBO 3.1 program ${ }^{31}$ to obtain a NBO energy $\left(E_{\mathrm{NBO}, \mathrm{C}-\mathrm{C}(\pi)}\right)$ corresponding to the $\pi$ orbital of a C-C double bond of the CBDs. More details about the model development and the application procedure are given elsewhere. ${ }^{27}$

\section{Kinetic modeling}

Kinetic simulations using Kintecus $5.00^{32}$ were performed to derive the respective $k^{\prime}$ for photoisomerization and other phototransformation processes of $(Z)$ - and $(E)-1,1,3,4$-TCBDs in a mixture (Text S5) and to derive a simulated abatement of CBDs based on derived $k^{\prime}$-values (Table 2).

\section{Results and discussion}

\section{Kinetics of the reactions of CBDs with ozone $\left(k_{03, \exp }\right)$}

The experimentally determined $k_{\mathrm{O} 3}\left(k_{\mathrm{O} 3 \text {,exp }}\right)$ are shown in Table $1 . k_{\mathrm{O} 3 \text {,exp }}$-values for the 9 CBDs ranged over more than 4 orders of magnitude: TCBDs $\left(1.6 \times 10^{2}-7.8 \times 10^{3} \mathrm{M}^{-1} \mathrm{~s}^{-1}\right)$, PCBDs $\left(1-10 \mathrm{M}^{-1} \mathrm{~s}^{-1}\right)$, and $\operatorname{HCBD}\left(<0.1 \mathrm{M}^{-1} \mathrm{~s}^{-1}\right)$. Note that $(E)$ - and $(Z)-1,1,3,4-\mathrm{TCBD}$ was ozonated as a mixture as received from the supplier. Nonetheless, the obtained $k_{\mathrm{O} \text {,exp }}$-values are considered to be valid because the ozone concentration is in excess ( $>15$ fold) to $1,1,3,4-$ TCBDs ensuring that each isomer degrades independently of the other isomer. $k_{\mathrm{O} 3 \text {,exp }}$ for 
159 HCBD could not be determined because no appreciable degradation was observed under the 160 experimental conditions. Thus, $k_{\mathrm{O} 3 \text {,exp }}$ for $\mathrm{HCBD}$ was estimated to be $<0.1 \mathrm{M}^{-1} \mathrm{~s}^{-1}$ which is 161 the reported $k_{\mathrm{O} 3 \text {,exp }}$ range for $\mathrm{PCE} .^{33}$

162 Overall, with increasing chlorine substituents on CBDs from four to six, the $k_{\mathrm{O} \text {,exp }}$-values 163 decrease. This suggests the electron-withdrawing effect of chlorine substituents on $k_{03 \text {,exp }}$ for 164 CBDs is additive, which is in agreement with previous observations for chlorinated ethenes. ${ }^{34}$ 165 The range of $k_{\mathrm{O} 3 \text {,exp }}$ for TCBD and PCBD is similar to the range of $k_{\mathrm{O} 3 \text {,exp }}$ for dichloroethenes 166

(DCEs) $\left(1.1 \times 10^{2}-7.9 \times 10^{3} \mathrm{M}^{-1} \mathrm{~s}^{-1}\right)^{34}$ and TCE $\left(14 \mathrm{M}^{-1} \mathrm{~s}^{-1}\right),{ }^{34}$ respectively.

Differences in $k_{\mathrm{O} 3 \text {,exp }}$-values were noticeable between isomers with the same number of chlorine substituents: $\sim 10$-fold or $\sim 50$-fold for the two PCBD isomers or the six TCBDs isomers, respectively. This indicates that differing positions of the chlorine substituents influence electronic interactions of CBDs with ozone. Although this variation is not well understood, the cis effect may explain the specific observation that $k_{03 \text {,exp }}$ for $c i s-$ or $(Z)-1,1,3,4-\mathrm{TCBD}$ was lower than $k_{\mathrm{O} 3 \text {,exp }}$ for trans- or $(E)-1,1,3,4-\mathrm{TCBD}$ by a factor of $\sim 2.4$. The cis effect is a phenomenon that the cis-isomer is more stable compared to the trans-isomer for 1,2difluoroethene and 1,2-DCE ${ }^{35-37}$ and was also observed in $k_{\mathrm{O} 3}$ for 1,2-DCE: $k_{\mathrm{O} 3}$ for $(Z)-1,2-$ $\operatorname{DCE}\left(5.4 \times 10^{2} \mathrm{M}^{-1} \mathrm{~s}^{-1}\right)$ is ten times lower than $k_{\mathrm{O} 3}$ for $(E)-1,2-\mathrm{DCE}\left(6.5 \times 10^{3} \mathrm{M}^{-1} \mathrm{~s}^{-1}\right) \cdot{ }^{34}$

\section{Prediction of rate constants for the reactions of CBDs with ozone $\left(\boldsymbol{k}_{\mathrm{O3}, \mathrm{pred}}\right)$}

$k_{\mathrm{O} 3}$-values for $\mathrm{CBDs}$ were predicted by taking into account (non)-planar $\mathrm{CBD}$ conformers using the previously developed quantum chemical model for olefins (Table 1). ${ }^{27}$ Detailed procedures and discussion for deriving a predicted $k_{\mathrm{O} 3}$ are presented in Text $\mathrm{S} 4$. A $k_{\mathrm{O} 3}$ prediction procedure is briefly demonstrated for $(E)-1,1,2,4$-TCBD in Figure 2 where two conformers corresponding to minima in the potential energy curve (PEC) were found: The first con- 
182 former has a dihedral angle (i.e., the angle between the planes comprising the atoms $\mathrm{C}_{1}-\mathrm{C}_{2}-\mathrm{C}_{3}$ and $\mathrm{C}_{2}-\mathrm{C}_{3}-\mathrm{C}_{4}$ in Figure 2, respectively) of $0^{\circ}$ and the other $116^{\circ}$ (Text $\mathrm{S} 4$ for more details). The planar $s$-trans global minimum conformer $\left(\varphi=0^{\circ}\right)$ of $(E)-1,1,2,4$-TCBD reads $-11.50 \mathrm{eV}$ and $-12.77 \mathrm{eV}$ of $E_{\mathrm{NBO}, \mathrm{C}-\mathrm{C}(\pi)}$ (open circles) for the two $\mathrm{C}=\mathrm{C}$ bonds, respectively. Based on a linear regression equation $\left(\log k_{\mathrm{O} 3}=1.32 \times E_{\mathrm{NBO}, \mathrm{C}-\mathrm{C}(\pi)}+18.54\right.$ for the HF/6-311++G** method) ${ }^{27} k_{\mathrm{O} 3, \operatorname{global}(\mathrm{C} 1=\mathrm{C} 2)}=48 \mathrm{M}^{-1} \mathrm{~s}^{-1}$ and $k_{\mathrm{O} 3, \operatorname{global}(\mathrm{C} 3=\mathrm{C} 4)}=2265 \mathrm{M}^{-1} \mathrm{~s}^{-1}$ were obtained, respectively, resulting in $2314 \mathrm{M}^{-1} \mathrm{~s}^{-1}$ for a species-specific second-order rate constant $\left(k_{\mathrm{O} 3 \text {, global }}\right)$ for the global conformer based on Eq. S5. As expected, the $\mathrm{C}=\mathrm{C}$ bond with a higher chlorine substitution had a lower $k_{\mathrm{O} 3}$. In the same manner, $k_{\mathrm{O} 3}$, local of $1378 \mathrm{M}^{-1} \mathrm{~s}^{-1}$ was obtained for the gauche local minimum conformer $\left(\varphi=116^{\circ}\right)$. Applying Eq. S6 with $k_{\mathrm{O} 3}$-values for global and local conformers and their relative populations ( $p_{i}$ in Table S3), $k_{\mathrm{O} 3 \text {,pred }}$ for $(E)-1,1,2,4-\mathrm{CBD}$ was predicted to be $2.3 \times 10^{3} \mathrm{M}^{-1} \mathrm{~s}^{-1}$ with a prediction error of a factor of $\sim 3$ from $k_{\mathrm{O} 3 \text {, exp }}=$ $7.8 \times 10^{3} \mathrm{M}^{-1} \mathrm{~s}^{-1}$.

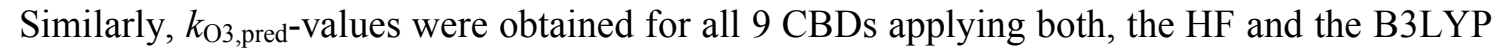
methods (Table 1). $k_{\mathrm{O} 3}$ values could be predicted within about a factor of 4 of the experimental $k_{\mathrm{O} 3}$ for the TCBDs (Figure S6), which is comparable to the performance of the applied prediction model for olefins (on average a factor of 3.4) ${ }^{27}$. In contrast, an overestimation of predicted $k_{\mathrm{O} 3}$ values occurred for the two PCBDs and HCBD by more than an order of magnitude. This may be caused by steric hindrances by chlorine substituents for the orbital interaction between ozone and $\mathrm{PCBD} / \mathrm{HCBD}$, which are not taken into account in $E_{\mathrm{NBO}, \mathrm{C}-\mathrm{C}(\pi)}$ calculations. Alternatively, the $\mathrm{C}=\mathrm{C}$ bond is so electron-poor that the formation of a cyclic ozonide $^{24,34}$ is no longer dominant. Therefore, the reactivity of PCBDs and HCBD with ozone cannot be interpreted by only $E_{\mathrm{NBO}, \mathrm{C}-\mathrm{C}(\pi)}$. 


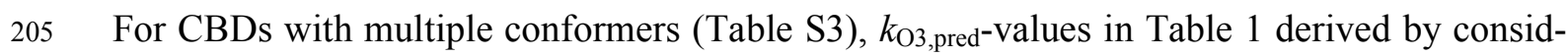

ering both global and local minimum conformers (i.e., $k_{\mathrm{O} \text {,global }}, k_{\mathrm{O} 3 \text {,local, }}$ and their relative populations) based on Eq. S6 are almost the same as $k_{03 \text {,global }}$ in Table S4. This suggests that the contribution of a local minimum conformer (i.e., $k_{\mathrm{O} 3 \text {,local }}$ ) to $k_{\mathrm{O} 3 \text {,pred }}$ is insignificant, which is understood by the predominant population of a global minimum (Table S3). Moreover, the difference between $k_{\mathrm{O} 3 \text {,global }}$ and $k_{\mathrm{O} 3 \text {,local }}$ is less than a factor of 2 except for 1,1,4,4-TCBD ( 3 and $\sim 4$ folds for HF and B3LYP method, respectively). Therefore, it seems that $k_{\mathrm{O} \text {,global }}$ can be used as a good approximation. However, it should be noted that this does not justify the general representability of $k_{\mathrm{O} \text {,global }}$ for other compounds.

\section{Kinetics for the reaction of CBDs with hydroxyl radical $\left(k_{\bullet \circ H}\right)$}

Experimenatally determined $k_{\cdot} \mathrm{OH}^{-}$values for 9 CBDs are presented in Table 1 . The determined $k \cdot \mathrm{OH}^{-}$values are higher than $5 \times 10^{9} \mathrm{M}^{-1} \mathrm{~s}^{-1}$ for all TCBDs except $1,1,2,3-\mathrm{TCBD}\left(3.4 \times 10^{9}\right.$ $\left.\mathrm{M}^{-1} \mathrm{~s}^{-1}\right)$. A lower reactivity with ${ }^{\circ} \mathrm{OH}$ was observed for the 2 PCBDs $\left(2.1 \times 10^{9} \mathrm{M}^{-1} \mathrm{~s}^{-1}\right.$ and $\left.3.9 \times 10^{9} \mathrm{M}^{-1} \mathrm{~s}^{-1}\right)$, followed by the lowest reactivity for $\operatorname{HCBD}\left(0.9 \times 10^{9} \mathrm{M}^{-1} \mathrm{~s}^{-1}\right)$. Overall, a higher chlorine substitution of CBD leads to a lower reactivity with ${ }^{\circ} \mathrm{OH}$. Decreased $k_{\bullet} \cdot \mathrm{OH}$ with increasing chlorine substitution was also observed for chlorinated ethenes: $3.8 \times 10^{9} \mathrm{M}^{-1} \mathrm{~s}^{-1}$, $2.8 \times 10^{9} \mathrm{M}^{-1} \mathrm{~s}^{-1}$, and $2.0 \times 10^{9} \mathrm{M}^{-1} \mathrm{~s}^{-1}$ for cis-1,2-DCE, TCE, and PCE, respectively. ${ }^{38}$

\section{Determination of fluence-based first-order rate constants $\left(k^{\prime}\right)$, molar absorption coeffi-} cients $(\varepsilon)$, and quantum yields $(\Phi)$

Fluence-based first-order rate constants $\left(k^{\prime}\right)$ and photoisomerization processes. The determined $k^{\prime}$-values based on Eq. 1 ranged from $210 \pm 30 \mathrm{~m}^{2}$ einstein $^{-1}$ for $1,1,4,4-\mathrm{TCBD}$ to $2730 \pm 440 \mathrm{~m}^{2}$ einstein $^{-1}$ for $(Z, Z)-1,2,3,4-\mathrm{TCBD}$, respectively. Two $k^{\prime}$-values were reported 
227 for $(E)-1,1,3,4-$ and $(Z)-1,1,3,4-\mathrm{TCBDs}$ for separate photoisomerization and other phototransformation processes (see below).

A noticeable formation of photo-products was detected by GC/MS analyses for $(E)-1,1,2,4-$, (Z)- and $(E)-1,1,3,4-$ as a mixture, $(Z, Z)-1,2,3,4-$ TCBD and $(Z)-1,1,2,3,4$-PCBD (Figures 3 and S7). Because of their identical mass fragmentation patterns to those of the parent compounds (Figure S7), these products are considered to be the isomers of the parent CBDs, and are termed as photoisomers hereafter. No other confirmative examinations of their molecular structure than the mass fragmentation were used.

Only relative responses of the photoisomers are presented in Figure 3 for $(E)-1,1,2,4-$ and (Z,Z)-1,2,3,4-TCBD and (Z)-1,1,2,3,4-PCBD because there were no commercially available standards. The relative response was calculated as the peak area of the parent CBD or its photoisomers divided by the initial peak area of the parent CBD (all peak areas corrected by normalization to the internal standard). Thus, the relative response should not be interpreted as a concentration but only as semi-quantitative information.

Photoisomerization of less than $40 \%$ relative to the parent CBD based on the relative response were observed for (E)-1,1,2,4-TCBD (Figure 3a) and (Z)-1,1,2,3,4-PCBD (Figure 3d), whereas a significant conversion of up to $85 \%$ was observed for $(Z, Z)-1,2,3,4$-TCBD (Figure $3 b)$. For UV irradiation (254 $\mathrm{nm}$ ) of the mixture of $(E)$ - and $(Z)-1,1,3,4-\mathrm{TCBD}$ (Figure $3 \mathrm{c}$ ), a slight increase in concentration was observed for $(E)-1,1,3,4$-TCBD up to a UV photon fluence of 1 meinstein $\mathrm{m}^{-2}$, while a significant degradation $(>50 \%)$ of $(Z)-1,1,3,4-\mathrm{TCBD}$ occurred for the same UV dose. This indicates that a photoisomerization of the $(Z)-1,1,3,4-$ to the $(E)-1,1,3,4-$ TCBD occurs. 
249 As rotation about a double bond is allowed in excited electronic states of organic compounds, all the CBDs with a $Z$ or $E$ configuration can undergo photoisomerization. Depending on the substitution pattern of the chlorine atoms, $Z$ and $E$ configuration pairs or $(Z, Z),(E, Z)$ and $(E, E)$ configuration triads are possible for photoisomerizable CBDs. Once formed, a photoisomer in the absence of UV light (e.g., after UV treatment) would not revert to the parent CBD because of a high energy barrier for the internal rotation of a C-C double bond.

In the case of $(Z, Z)-1,2,3,4-\mathrm{TCBD}$, photoisomerization is proposed to occur following Scheme 1, which accounts for the formation of the two observed photoisomers (see Figure 3b). Thereby, the peaks with a higher relative response (photoisomer-1 in Figures $3 \mathrm{~b}$ and S7) and a lower relative response (photoisomer-2) were assigned to be the $(Z, E)$-photoisomer and the $(E, E)$-photoisomer, respectively, assuming a stepwise conversions (Scheme 1).

For $(E)-1,1,2,4-$ TCBD two photoisomers were detected (Figure 3a and S7), although only one photoisomer is predicted for an $E-Z$ photoisomerization reaction. The additional photoisomer could be the result of a photocyclization reaction. Indeed, the formation of cyclobutene and cyclopropene isomers has been shown to occur upon direct UV irradiation of 1,3-dienes. ${ }^{39,40}$ Only one photoisomer was observed for (Z)-1,1,2,3,4-PCBD, which was assigned to its $E$ configuration.

$k_{\mathrm{CBD}, 254 \mathrm{~nm}}$ in Eq. 1 determined for photo-isomerizable CBDs takes into account both photoisomerization and other phototransformations. This propagates into $\Phi_{254 \mathrm{~nm}}$ and $k^{\prime}$ reported

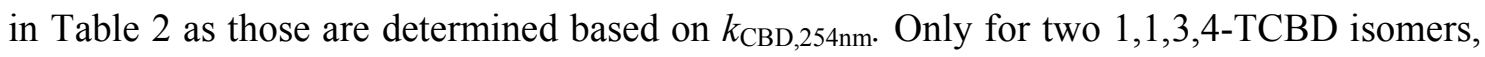
both photochemical processes could be differentiated by kinetic simulations because standards were available (see Text S5 and Figure S8 for more details), yielding the individual $\Phi_{254 \mathrm{~nm}^{-}}$and $k^{\prime}$-values in Table 2. 
Molar absorption coefficients $(\varepsilon)$. The determined $\varepsilon_{254 \mathrm{~nm}}$ for the 9 selected CBDs are summarized in Table 2 . The $\varepsilon_{254 \mathrm{~nm}}$-values for $1,1,2,3-\mathrm{TCBD}, 1,1,2,4,4-\mathrm{PCBD}$, and HCBD are in the order of $10^{2} \mathrm{~m}^{2} \mathrm{~mol}^{-1}$, whereas they are in the order of $10^{3} \mathrm{~m}^{2} \mathrm{~mol}^{-1}$ for $(E)-1,1,2,4-, 1,1,4,4-$, and $(Z, Z)-1,2,3,4-T C B D$ and (Z)-1,1,2,3,4-PCBD (Table 2 and Figure S5). Note that since there were no separate standards available for the individual isomers, an average $\varepsilon_{254 \mathrm{~nm}}$ was determined for the isomer mixture of $(E)-1,1,3,4-$ and $(Z)-1,1,3,4$-TCBDs.

Quantum yields $(\Phi)$. The determined $\Phi_{254 \mathrm{~nm}}$ values based on Eq. 2 are presented in Table 2 . They vary between 0.03 and 0.95 , where the highest and the lowest $\Phi_{254 \mathrm{~nm}}$ were determined for HCBD and 1,1,4,4-TCBD, respectively. Note that $\Phi_{254 \mathrm{~nm}}$ for $(E)-1,1,3,4-$ and $(Z)-1,1,3,4-$ TCBD were determined using an average $\varepsilon_{254 \mathrm{~nm}}$ of their isomer mixture.

\section{Abatement of CBDs and micropollutants and bromate formation in a natural ground- water during ozonation, direct UV photolysis, and the $\mathrm{AOPs} \mathrm{O}_{3} / \mathrm{H}_{2} \mathrm{O}_{2}$ and $\mathrm{UV} / \mathrm{H}_{2} \mathrm{O}_{2}$}

Ozonation and $\mathrm{O}_{3} / \mathrm{H}_{2} \mathrm{O}_{2}$. Figure 4 shows the abatement of 7 selected CBDs and 3 micropollutants as well as the bromate formation during ozonation and the AOP $\mathrm{O}_{3} / \mathrm{H}_{2} \mathrm{O}_{2}$ in Hardwald groundwater. For $0.5 \mathrm{mg} \mathrm{O} / \mathrm{L},>95 \%$ abatement (based on the calibration range) was observed for all TCBDs, whereas $47 \%$ and $16 \%$ abatement was obtained for $(Z)-1,1,2,3,4-$ PCBD and HCBD, respectively. A gradual increase in degradation was observed for $(Z)$ $1,1,2,3,4-\mathrm{PCBD}$ by increasing the ozone dose to $4.0 \mathrm{mgO}_{3} / \mathrm{L}$ achieving $>95 \%$ abatement, while an abatement of up to $40 \%$ was observed for HCBD.

The abatement of micropollutants was also investigated not only to compare them with the abatement of CBDs based on their known kinetic parameters (i.e., $k_{\mathrm{O} 3}$ and $k_{\bullet} \cdot \mathrm{H}$ ) but also to highlight the additional benefits in terms of general oxidative abatement of aqueous contaminants during ozonation. Among the 5 micropollutants investigated, carbamazepine and tra- 
madol are not presented in Figure 4 because a complete abatement was always observed due to high $k_{\mathrm{O} 3}$-values of $3 \times 10^{5} \mathrm{M}^{-1} \mathrm{~s}^{-1}{ }^{41}$ for carbamazepine and $3.8 \times 10^{4} \mathrm{M}^{-1} \mathrm{~s}^{-1} 42$ for tramadol at pH 8.0, respectively. Benzotriazole shows similar degradation efficiencies as TCBDs, which can be explained by the similar $k_{03}$-values $\left(\sim 1.0 \times 10^{3} \mathrm{M}^{-1} \mathrm{~s}^{-1}\right.$ at $\mathrm{pH} 8.0$ for benzotriazole $\left.{ }^{24}\right)$. The degradation of iopamidol is comparable to $(Z)-1,1,2,3,4-\mathrm{PCBD}$, which is consistent with rather similar $k_{\mathrm{O} 3}$ and $k_{\cdot \mathrm{OH}}\left(k_{\mathrm{O} 3}=<0.8 \mathrm{M}^{-1} \mathrm{~s}^{-143}\right.$ and $k_{\bullet \mathrm{OH}}=3.34 \times 10^{9} \mathrm{M}^{-1} \mathrm{~s}^{-1}{ }^{44}$ for iopamidol and $k_{\mathrm{O} 3}=1.0 \mathrm{M}^{-1} \mathrm{~s}^{-1}$ and $k_{\cdot \mathrm{OH}}=2.2 \times 10^{9} \mathrm{M}^{-1} \mathrm{~s}^{-1}$ for $(Z)-1,1,2,3,4-\mathrm{PCBD}$, this study). A higher abatement efficiency was observed for diatrizoate compared to HCBD. While two $k_{\bullet} \cdot \mathrm{OH}^{-}$ values are reported for diatrizoate, namely, $0.5 \times 10^{9} \mathrm{M}^{-1} \mathrm{~s}^{-145}$ and $0.9 \times 10^{9} \mathrm{M}^{-1} \mathrm{~s}^{-1} 44,0.9 \times 10^{9}$ $\mathrm{M}^{-1} \mathrm{~s}^{-1}$ was determined for HCBD in this study (Table 1).

Overall $\mathrm{H}_{2} \mathrm{O}_{2}$ addition led to a lower abatement efficiencies of the investigated compounds (Figure 4). For ozone-reactive TCBDs and benzotriazole, it may be due to a decreased ozone exposure by a fast transformation of ozone to ${ }^{\circ} \mathrm{OH}$ by hydrogen peroxide (mainly by $\left.\mathrm{HO}_{2}{ }^{-}\right)^{24}$ For ozone-resistant PCBD, HCBD, iopamidol, and diatrizoate, it may be due to an increased 'OH scavenging rate by added hydrogen peroxide (both $\mathrm{H}_{2} \mathrm{O}_{2}$ and $\mathrm{HO}_{2}{ }^{-}$) (e.g., about $8 \%$ increase of ${ }^{\circ} \mathrm{OH}$ scavenging rate $\left(\mathrm{s}^{-1}\right)$ was estimated for $\mathrm{H}_{2} \mathrm{O}_{2} / \mathrm{O}_{3}=2.0(\mathrm{w} / \mathrm{w})$ and $\mathrm{O}_{3}=2.0$ $\mathrm{mg} / \mathrm{L})$.

Bromate formation dramatically increased with increasing ozone doses from $1.3 \mu \mathrm{g} / \mathrm{L}$ for $0.25 \mathrm{mgO}_{3} / \mathrm{L}$ to $56-66 \mu \mathrm{g} / \mathrm{L}$ for the higher ozone doses $\left(1.0-4.0 \mathrm{mgO}_{3} / \mathrm{L}\right)($ Figure 4$)$, which corresponds to $31-37 \%$ molar conversion from bromide. Upon $\mathrm{H}_{2} \mathrm{O}_{2}$ addition up to 1.0 $\mathrm{mgO}_{3} / \mathrm{L}$, the bromate formation was significantly reduced to below $10 \mu \mathrm{g} / \mathrm{L}$, the drinking water standard in Switzerland, ${ }^{46} \mathrm{EU},{ }^{47}$ and USA. ${ }^{48}$ The bromate concentrations remained above $10 \mu \mathrm{g} / \mathrm{L}$ for the higher ozone doses except for $2.0 \mathrm{mgO}_{3} / \mathrm{L}$ with $\mathrm{H}_{2} \mathrm{O}_{2} / \mathrm{O}_{3}=2.0(\mathrm{w} / \mathrm{w})$. 
318 The reduced bromate formation is attributable to the decreased ozone exposure caused by $\mathrm{H}_{2} \mathrm{O}_{2}$ addition, as explained above for TCBDs and benzotriazole.

Direct $U V$ photolysis and $U V / H_{2} \mathrm{O}_{2}$. Direct UV photolysis for the 7 selected CBDs was compared with a simulated degradation based on the $k^{\prime}$-values in Table 2 (Figure 5). Overall, the model could predict the $\%$ abatement up to $50 \%$ relatively well for all CBDs (red lines in Figure 5). For further degradation, relatively good predictions were observed for $(E)-1,1,3,4-$ and 1,1,4,4-TCBD and HCBD. In contrast, poor predictions were obtained for $(E)-1,1,2,4-$, (Z)-1,1,3,4, and (Z,Z)-1,2,3,4-TCBD and (Z)-1,1,2,3,4-PCBD, which is due to an appearance of a plateau without further degradation. Interestingly, the CBDs with a poor prediction coincided with photo-isomerizable compounds except for $(E)-1,1,3,4-\mathrm{TCBD}$. The concentration even slightly increased for $(Z, Z)-1,2,3,4-\mathrm{TCBD}$. Concurrently with the appearance of a plateau, the enhanced formation of photoisomers was observed in a groundwater compared to a buffered purified water. For example, the maximum relative response of the photoisomer-1 of (Z,Z)-1,2,3,4-TCBD was $\sim 0.9$ and $\sim 1.6$ in a buffered purified water (Figure 3a) and a groundwater (Figure 5), respectively. This phenomenon might be related to interactions between CBDs and the dissolved organic matter (DOM) present in groundwater. On the one hand, excited triplet states of the DOM, which are formed upon UV irradiation of DOM, ${ }^{49}$ have been shown to induce photoisomerization of conjugated dienes by triplet-triplet energy transfer. ${ }^{50}$ However, this effect is expected to be minor because of the high rates of direct photoisomerization at $254 \mathrm{~nm}$. On the other hand, hydrophobic CBDs are expected to sorb to DOM, thus forming supramolecular assemblies. This might have complex consequences for the photoisomerization of CBDs including enhanced photoisomerization rates due to energy transfer from excited singlet or triplet DOM to the CBDs, reduced photoisomerization rates 
due to hindered internal rotation, and/or additional deactivation processes such as energy transfer from excited CBDs to DOM.

Although some enhancements $(\sim 10 \%)$ and inhibitions $(\sim 15 \%)$ were seemingly observed for (E)-1,1,3,4- and 1,1,4,4-TCBDs and (Z)-1,1,2,3,4-PCBD and HCBD (Figure 5), respectively, no significant effect on the degradation of the investigated CBDs seemed to manifest upon $\mathrm{H}_{2} \mathrm{O}_{2}$ addition. This may be mainly due to the efficient UV phototransformation of CBDs. For non-photoisomerizable CBDs such as 1,1,4,4-TCBD and HCBD, the matrix effect of the groundwater seems to play a minor role because their degradation could be well predicted using direct UV photolysis parameters determined in purified water.

\section{Practical implications}

During ozonation $50-100 \%$ of the TCBDs were abated at ozone doses of $0.25-1.0 \mathrm{mgO}_{3} / \mathrm{L}$. The abatement efficiencies were smaller for PCBD and HCBD. Overall abatement efficiencies were consistent between CBDs and other selected micropollutants when evaluated based on the corresponding experimental $k_{\mathrm{O} 3}$ and $k_{\bullet} \cdot \mathrm{OH}$ determined in this study. With $k_{\mathrm{O} 3}$ and $k \cdot \mathrm{OH}$, the abatement efficiency of CBDs can be estimated by characterizing the evolution of both ozone and ${ }^{\circ} \mathrm{OH}$ (i.e., oxidant exposures) for a specific ozone dose in a water sample of interest. $^{51} k_{\mathrm{O} 3}$ predictions for TCBDs by quantum chemical models can be an alternative to an empirical $k_{\mathrm{O} 3}$ determination. $\mathrm{H}_{2} \mathrm{O}_{2}$ addition is advantageous for minimizing the bromate formation during ozonation, however, it may lead to a decreased abatement of CBDs or micropollutants. Therefore, the ozone and $\mathrm{H}_{2} \mathrm{O}_{2}$ doses have to be carefully optimized to maximize pollutant abatement and to minimize bromate formation. For a typical UV dose for disinfection $\left(400 \mathrm{~J} / \mathrm{m}^{2}\right)$, various degrees of phototransformation could be achieved for the investigated CBDs from $10 \%$ for $1,1,4,4-\mathrm{TCBD}$ to $90 \%$ for $(Z, Z)-1,2,3,4-\mathrm{TCBD}$. However, photoisomers can be formed from $\mathrm{CBDs}$ with $E / Z$ configuration. As the photoisomers are ex- 
365 pected to possess physico-chemical properties and toxicological effects similar to the parent 366 CBDs based on the analogous chemical compositions, associated effects must be taken into 367 account for assessing the benefits/potential drawbacks of this treatment process. The benefi368 cial effect of $\mathrm{H}_{2} \mathrm{O}_{2}$ addtion on the UV-induced abatement of CBDs in the tested groundwater 369 was observed to be minor $(<10 \%)$.

\section{Acknowlegements}

This study was funded by the project "Regional Water Supply Baselland 21". The authors thank Jakov Bolotin (Eawag), Elisabeth Salhi (Eawag), and Ursula Schönenberger (Eawag) for technical support and Frank Leresche (EPFL/Eawag) and Holger Lutze (Universität Duisburg-Essen) for fruitful discussions. The NMR hardware was partially granted by the Swiss National Science Foundation (SNFS, grant no. 206021_150638/1).

Supporting Information. List of standards and reagents, analytical methods, experimental procedures, and additional experimental/modeling data. 
380 Table 1. Experimental $k_{\mathrm{O} 3}\left(k_{\mathrm{O} 3 \text {, exp }}\right)$ and predicted $k_{\mathrm{O} 3}\left(k_{\mathrm{O} 3 \text {,pred }}\right)$ and experimental $k_{\bullet \mathrm{OH}}$ for the reactions of 381 CBDs with ozone or hydroxyl radicals.

\begin{tabular}{|c|c|c|c|c|}
\hline \multirow{2}{*}{ Compound } & \multirow{2}{*}{$k_{03, \exp }{ }^{a}\left(N^{b}\right)$} & \multicolumn{2}{|c|}{$k_{03, \text { pred }}{ }^{2}$} & \multirow{2}{*}{$k \cdot{ }^{\circ}{ }^{a}\left(N^{b}\right), \times 10^{9} \mathrm{M}^{-1} \mathrm{~s}^{-1}$} \\
\hline & & $\mathrm{HF} / 6-311++\mathrm{G}^{* *}$ & B3LYP/6-311++G** & \\
\hline 1,1,2,3-TCBD & $(3.0 \pm 0.6) \times 10^{2}(4)$ & $1.4 \times 10^{3}$ & $1.6 \times 10^{3}$ & $3.4 \pm 0.5(4)$ \\
\hline (E)-1,1,2,4-TCBD & $(7.8 \pm 1.0) \times 10^{3}(4)$ & $2.2 \times 10^{3}$ & $2.5 \times 10^{3}$ & $6.0 \pm 1.6(6)$ \\
\hline (E)-1,1,3,4-TCBD & $(1.1 \pm 0.2) \times 10^{3}(3)$ & $3.4 \times 10^{2}$ & $5.0 \times 10^{2}$ & $5.3 \pm 1.8(3)$ \\
\hline (Z)-1,1,3,4-TCBD & $(4.0 \pm 2.4) \times 10^{2}(3)$ & $3.6 \times 10^{2}$ & $5.7 \times 10^{2}$ & $5.7 \pm 3.2(3)$ \\
\hline $1,1,4,4-\mathrm{TCBD}$ & $(2.7 \pm 0.4) \times 10^{2}(3)$ & $6.9 \times 10^{2}$ & $1.0 \times 10^{3}$ & $5.4 \pm 0.8(5)$ \\
\hline$(Z, Z)-1,2,3,4-\mathrm{TCBD}$ & $(1.6 \pm 0.3) \times 10^{2}(3)$ & $4.2 \times 10^{2}$ & $6.0 \times 10^{2}$ & $7.1 \pm 1.5(6)$ \\
\hline (Z)-1,1,2,3,4-PCBD & $0.8 \pm 0.3(4)$ & $1.5 \times 10^{2}$ & $2.4 \times 10^{2}$ & $2.1 \pm 0.8$ (3) \\
\hline $1,1,2,4,4-\mathrm{PCBD}$ & $10.0 \pm 2.3(5)$ & $1.5 \times 10^{2}$ & $1.8 \times 10^{2}$ & $3.9 \pm 0.9(5)$ \\
\hline HCBD & $<0.1$ & 25 & 47 & $0.9 \pm 0.7(3)$ \\
\hline
\end{tabular}


386 Table 2. $\varepsilon_{254 n m}, \Phi_{254 n m}$, and $k^{\prime}$ determined for the 9 selected $\mathrm{CBDs}^{a}$

\begin{tabular}{|c|c|c|c|}
\hline Compound & $\varepsilon_{254 n m}{ }^{a}, \mathrm{~m}^{2} \mathrm{~mol}^{-1}$ & $\Phi_{254 n m}^{b}$, mol einstein ${ }^{-1}$ & $k^{\prime a}, \mathrm{~m}^{2}$ einstein ${ }^{-1}$ \\
\hline $1,1,2,3-\mathrm{TCBD}$ & $620 \pm 80$ & $0.22 \pm 0.04$ & $310 \pm 40$ \\
\hline (E)-1,1,2,4-TCBD & $2490 \pm 140$ & $0.14 \pm 0.04$ & $820 \pm 370$ \\
\hline (E)-1,1,3,4-TCBD & & $0.05 \pm 0.03^{d}, 0.07 \pm 0.04^{e}$ & $200 \pm 110^{d}, 270 \pm 150^{e}$ \\
\hline (Z)-1,1,3,4-TCBD & $1580 \pm 140^{c}$ & $0.13 \pm 0.11^{d}, 0.27 \pm 0.06^{e}$ & $1000 \pm 180^{d}, 460 \pm 400^{e}$ \\
\hline $1,1,4,4-\mathrm{TCBD}$ & $3210 \pm 100$ & $0.03 \pm 0.004$ & $210 \pm 30$ \\
\hline$(Z, Z)-1,2,3,4-\mathrm{TCBD}$ & $1620 \pm 140$ & $0.73 \pm 0.13$ & $2730 \pm 440$ \\
\hline (Z)-1,1,2,3,4-PCBD & $1110 \pm 470$ & $0.32 \pm 0.26$ & $810 \pm 560$ \\
\hline $1,1,2,4,4-\mathrm{PCBD}$ & $540 \pm 60$ & $0.37 \pm 0.09$ & $460 \pm 110$ \\
\hline HCBD & $230 \pm 60$ & $0.95 \pm 0.28$ & $510 \pm 110$ \\
\hline
\end{tabular}

${ }^{a} 95 \%$ confidence intervals determined by the student's $t$ test are given for all the reported values. ${ }^{b}$ Uncertainties estimated based on the error propagation through the multiplication of uncertainties in $k^{\prime}$ and $\varepsilon_{254 n m}$ for the respective CBDs. ${ }^{c}$ Average $\varepsilon_{254 n m}$ for the isomer mixture of $(E)-1,1,3,4-$ TCBD $(43 \%)$ and $(Z)-1,1,3,4-$ TCBD $(57 \%),{ }^{d}$ for photoisomerization, ${ }^{e}$ for other phototransformations. The number of replicates for determination of $k^{\prime}$ for CBDs is 3 except for $(E)-1,1,2,4-$ and $(Z, Z)-1,2,3,4-T C B D$ for which the number is 4. 


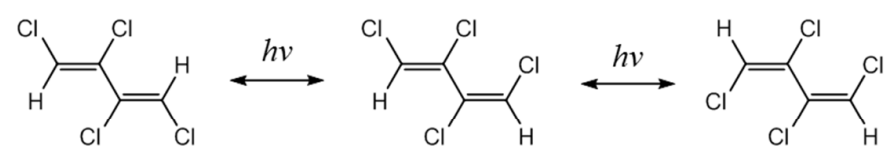

394 $(Z, Z)-1,2,3,4$

$(Z, E)-1,2,3,4$

$(E, E)-1,2,3,4$

395 Scheme 1 Proposed photoisomerization of $(Z, Z)-1,2,3,4-\mathrm{TCBD}$ to $(Z, E)-1,2,3,4-\mathrm{TCBD}$ and $(E, E)$ $396 \quad 1,2,3,4-\mathrm{TCBD}$. 


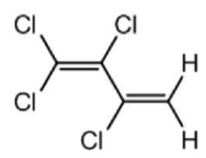

$1,1,2,3-\mathrm{TCBD}$

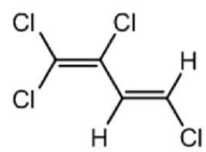

$(E)-1,1,2,4-\mathrm{TCBD}$

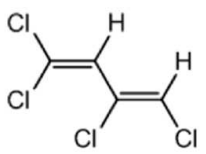

(Z)-1,1,3,4-TCBD
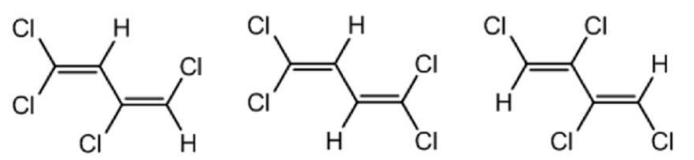

$(E)-1,1,3,4-T C B D$

1,1,4,4-TCBD

$(Z, Z)-1,2,3,4-T C B D$
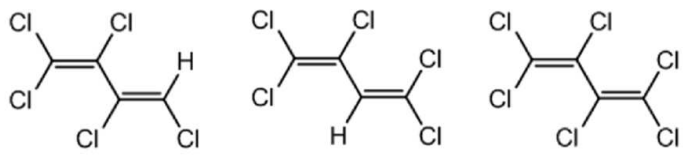

398

(Z)-1,1,2,3,4-PCBD

$1,1,2,4,4-\mathrm{PCBD}$

HCBD

399 Figure 1. Chemical structures of the selected 9 tetra-, penta-, and hexa-chlorobutadienes (TCBD, 400 PCBD, and HCBD, respectively) investigated in this study. 
402

403

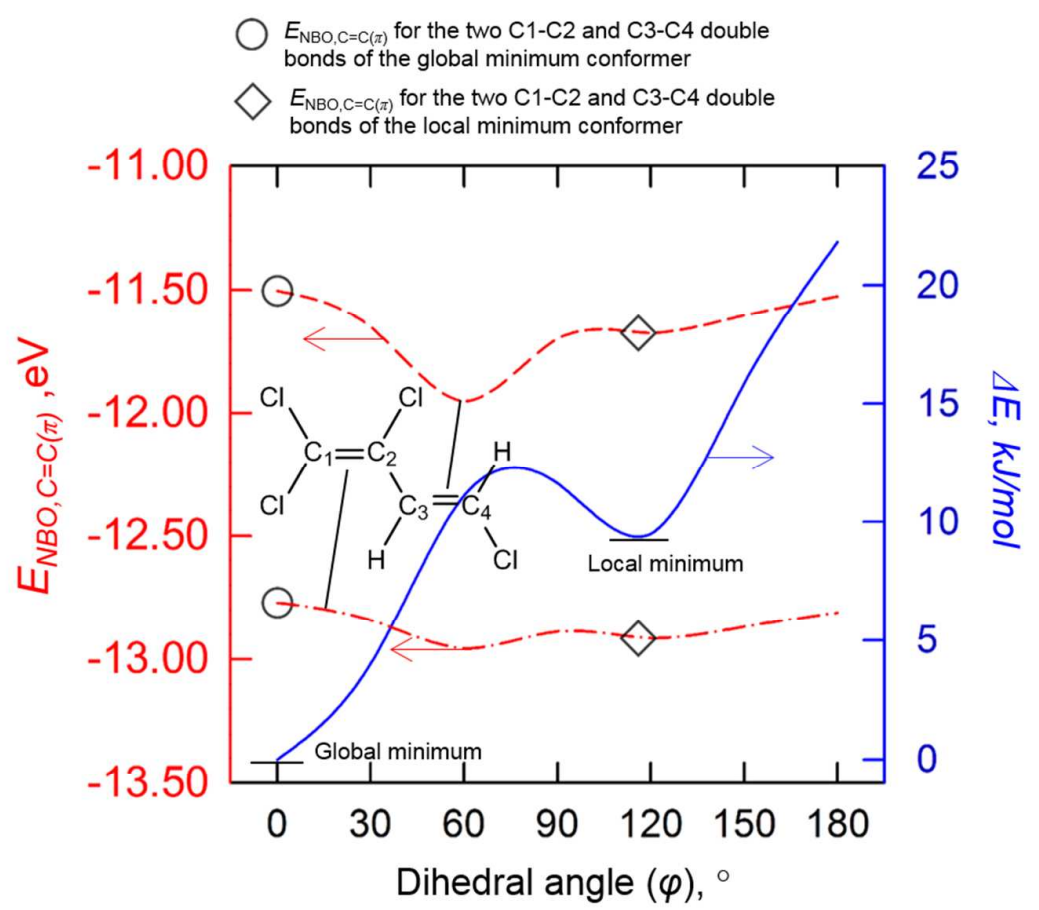

Figure 2. Profiles of the difference of a total electronic energy (blue solid line) $(\Delta E)$ of the $(E)-1,1,2,4-$ TCBD conformers and the lowest energy of the (E)-1,1,2,4-TCBD conformer and the corresponding natural bond orbital energy $\left(E_{\mathrm{NBO}, \mathrm{C}-\mathrm{C}(\pi)}\right)$ (red dash-dot line and red dashed line for the $\mathrm{C}_{1}-\mathrm{C}_{2}$ and $\mathrm{C}_{3}-\mathrm{C}_{4}$ double bonds, respectively) of the $\pi$ orbital of a C-C double bond of TCBD conformers as a function of the dihedral angle comprising the atoms $\mathrm{C}_{1}-\mathrm{C}_{2}-\mathrm{C}_{3}-\mathrm{C}_{4}$. All the energies were obtained at the HF/6$311++\mathrm{G}^{* *}$ level. 

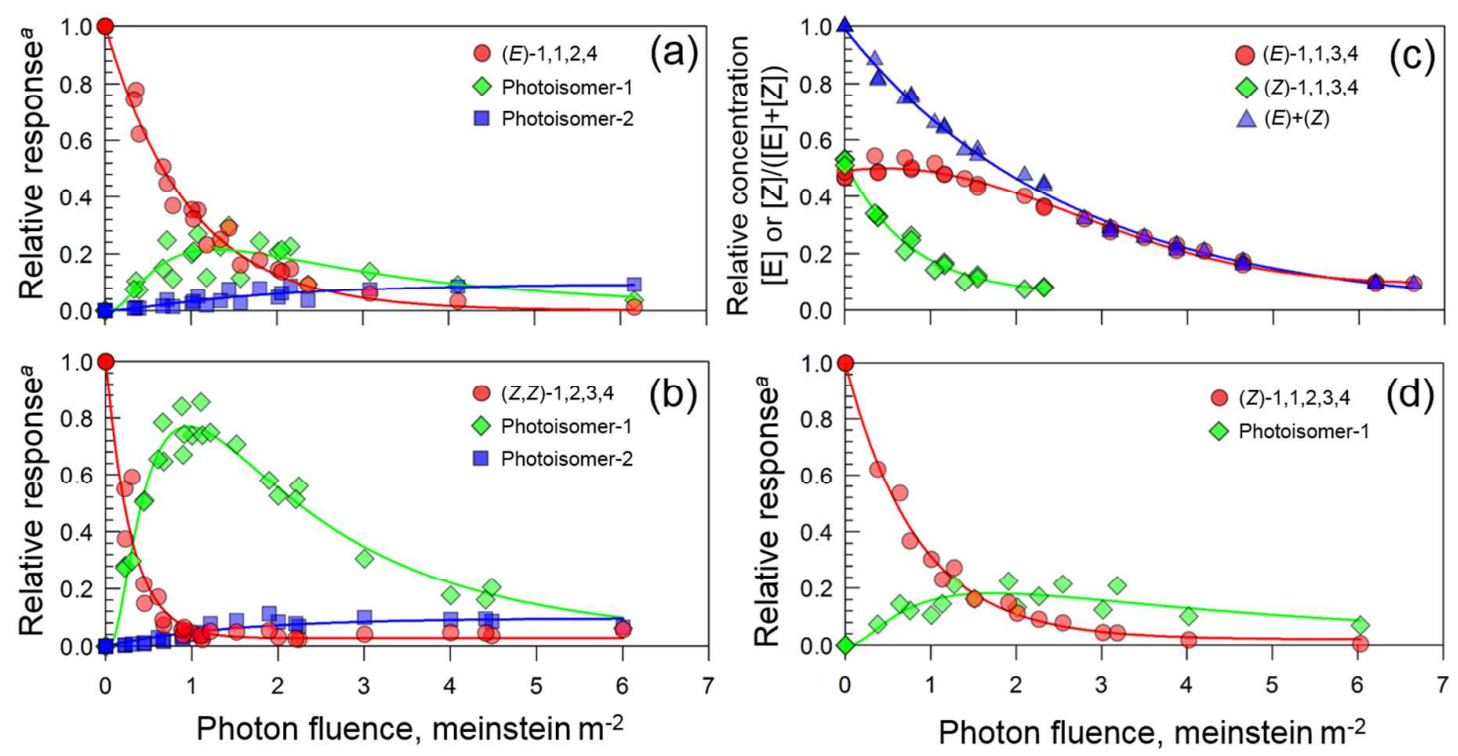

411

412

413

414

415

416

Figure 3. Evolution of (a) (E)-1,1,2,4-TCBD, (b) (Z,Z)-1,2,3,4-TCBD, (c) (E)-1,1,3,4- and (Z)-1,1,3,4TCBD, and (d) (Z)-1,1,2,3,4-PCBD and their photoisomers as a function of the photon fluence (meinstein $\mathrm{m}^{-2}$ ). ${ }^{a} \mathrm{~A}$ relative response is the peak area of the parent CBDs or its photoisomers dividied by the initial peak area of the parent CBD. All peak areas are normalized by the internal standard. Note that the curves, which were obtained by fitting the data, are shown only to guide the eye. 
Polychlorobutadienes

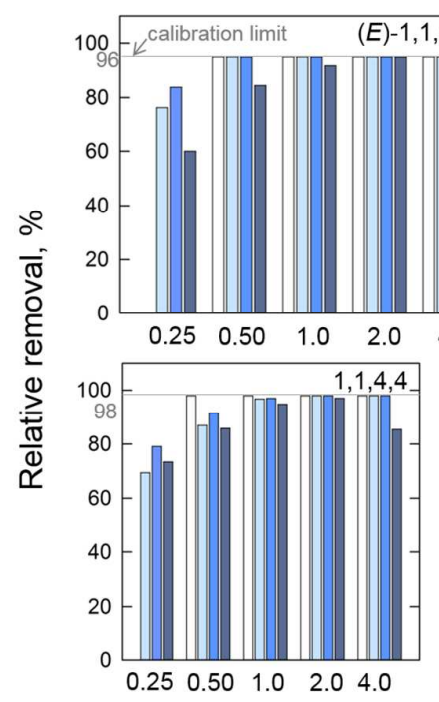

$-1,1,2,4$

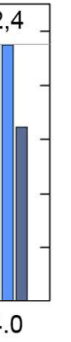

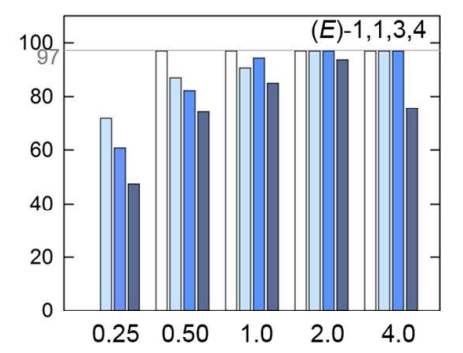
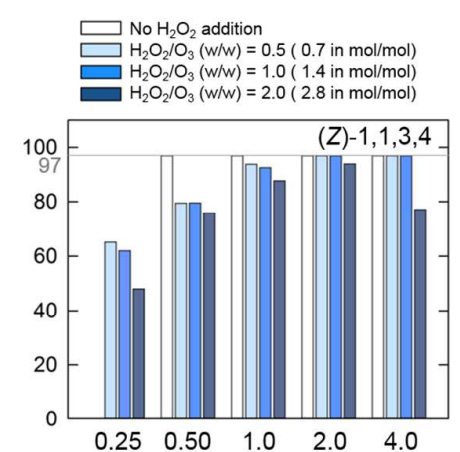

$\begin{array}{lllll}0.25 & 0.50 & 1.0 & 2.0 & 4.0\end{array}$
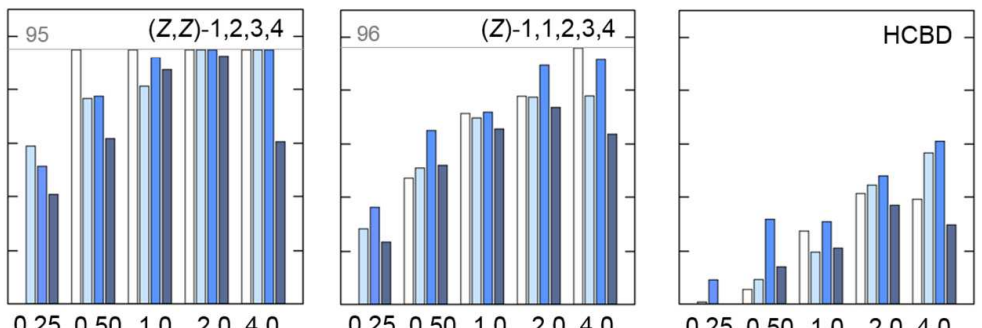

$\mathrm{O}_{3}$ dose, $\mathrm{mgO}_{3} / \mathrm{L}$

\section{Micropollutants \& Bromate $\left(\mathrm{BrO}_{3}^{-}\right)$}
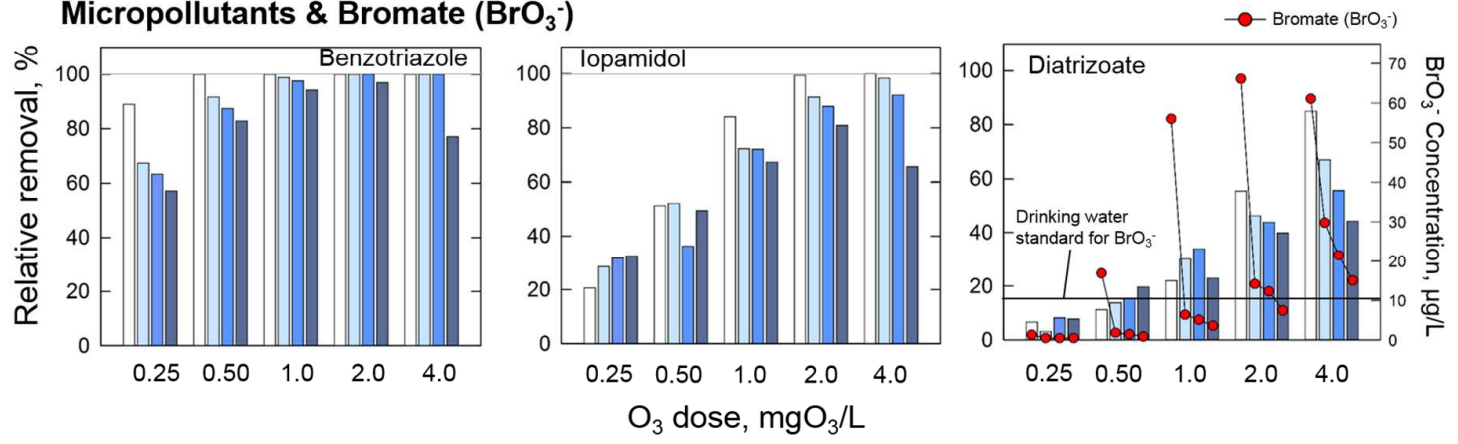

420

421

422

423

424

425

426

Figure 4. Abatement of CBDs and micropollutants and bromate formation during ozonation of Hardwald groundwater in the absence/presence of $\mathrm{H}_{2} \mathrm{O}_{2} . \mathrm{pH}=7.95-8.05$, temperature $=25^{\circ} \mathrm{C}$, and bromide concentration $=48 \mu \mathrm{g} / \mathrm{L}$. Note that the data for CBDs at $0.25 \mathrm{mgO}_{3} / \mathrm{L}$ without $\mathrm{H}_{2} \mathrm{O}_{2}$ are not presented because the sample was lost during analysis. The calibration limit was defined based on the lowest calibration concentration of an analyte. 


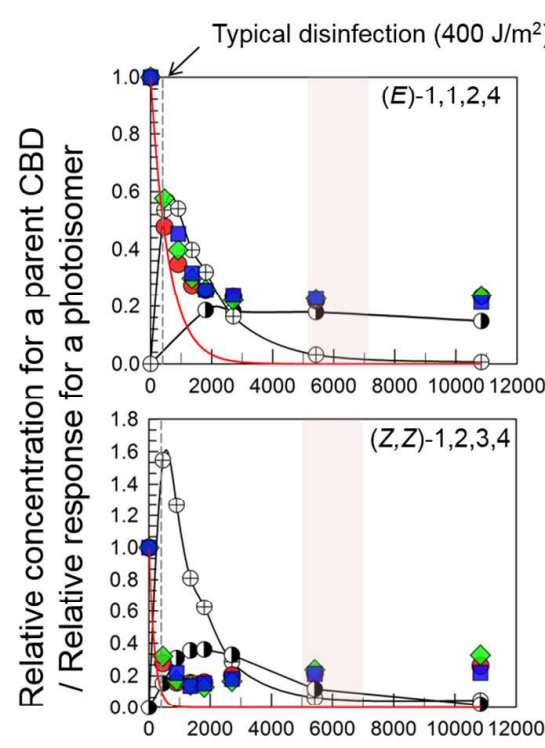

Figure 5. Abatement of CBDs during UV irradiation in absence/presence of $\mathrm{H}_{2} \mathrm{O}_{2}$ in Hardwald groundwater. A relative response is the peak area of the parent CBDs or its photoisomers divided by the initial peak area of the parent CBD. All peak areas are normalized by the internal standard. UV dose $\left(\mathrm{J} / \mathrm{m}^{2}\right)$ was calculated by the equation: $\mathrm{UV}$ dose $=E_{\mathrm{p}}{ }^{0} \times$ irradiation time $($ seconds $) \times \mathrm{U}$, where $\mathrm{U}=$ $4.72 \times 10^{5} \mathrm{~J}_{\text {einstein }}{ }^{-1}$ at $254 \mathrm{~nm} . \mathrm{pH}=7.95-8.05$ and temperature $=25^{\circ} \mathrm{C}$. Note that the data for a UV dose of about $360 \mathrm{~J} / \mathrm{m}^{2}$ for $\mathrm{H}_{2} \mathrm{O}_{2}=5.0 \mathrm{mg} / \mathrm{L}$ are not presented because the sample was lost during analysis.
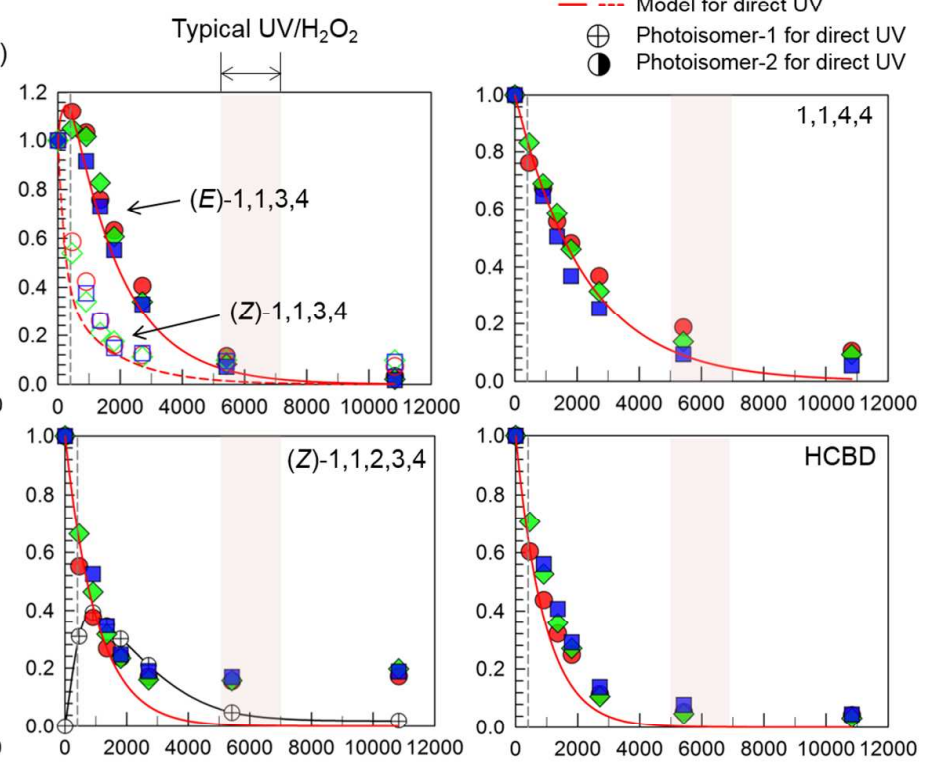


\section{References}

(1) Burkhard, L. P.; Sheedy, B. R.; McCauley, D. J.; DeGraeve, G. M. Bioaccumulation factors for chlorinated benzenes, chlorinated butadienes and hexachloroethane. Environ. Toxicol. Chem. 1997, 16, 1677-1686.

(2) Goldbach, R. W.; Van Genderen, H.; Leeuwangh, P. Hexachlorobutadiene residues in aquatic fauna from surface water fed by the river Rhine. Sci. Total Environ. 1976, 6, 31-40.

(3) Laska, A. L.; Bartell, C. K.; Laseter, J. L. Distribution of hexachlorobenzene and hexachlorobutadiene in water, soil, and selected aquatic organisms along the lower Mississippi River, Louisiana. Bull. Environ. Contam. Toxicol. 1976, 15, 535-542.

(4) Nikolaou, A. D.; Golfinopoulos, S. K.; Kostopoulou, M. N.; Kolokythas, G. A.; Lekkas, T. D. Determination of volatile organic compounds in surface waters and treated wastewater in Greece. Water Res. 2002, 36, 2883-2890.

(5) G. Oliver, Barry, L.E. Kaiser, K. Chlorinated organics in nearshore waters and tributaries of the St. Clair River. Water Poll. Res. J. Canada, 1986, 21, 344-350.

(6) Fattore, E.; Benfenati, E.; Fanelli, R. Analysis of Chlorinated 1,3-Butadienes by Solid-Phase Microextraction and Gas Chromatography-Mass Spectrometry. J. Chromatogr. A 1996, 737, $85-91$.

(7) Botta, D.; Dancelli, E.; Mantica, E. A Case History of Contamination by Polychloro-1,3butadiene Congeners. Environ. Sci. Technol. 1996, 30, 453-462.

(8) Brüschweiler, B. J. TTC-based risk assessment of tetrachlorobutadienes and pentachlorobutadienes--the in vitro genotoxic contaminants in ground and drinking water. Regul. Toxicol. Pharmacol. 2010, 58, 341-344.

(9) Barco-Bonilla, N.; Plaza-Bolaños, P.; Fernández-Moreno, J. L.; Romero-González, R.; Frenich, A. G.; Vidal, J. L. M. Determination of 19 volatile organic compounds in wastewater effluents from different treatments by purge and trap followed by gas-chromatography coupled to mass spectrometry. Anal. Bioanal. Chem. 2011, 400, 3537-3546.

(10) Agency for Toxic Substances and Disease Registry (ATSDR). Toxicological Profile for Hexachlorobutadiene; 1994.

(11) Hexachlorobutadiene in Drinking-water, Background document for development of WHO Guidelines for Drinking-water Quality, WHO/SDE/WSH/03.04/101; 2004.

(12) Stockholm Convention on Persistent Organic Pollutants.

(13) Directive 2000/60/EC of the European Parliament and of the Council of 23 October 2000 establishing a framework for Community action in the field of water policy, Off. J. Eur. Union, L 326, 2000.

(14) Decision No 2455/2001/EC of the European Parliament and of the Council of 20 November 2001 establishing the list of priority substances in the field of water policy and amending Directive 2000/60/EC, Off. J. Eur. Union, L331, 2001.

(15) Directive 2008/105/EC of the European Parliament and of the Council of 16 December 2008 on environmental quality standards in the field of water policy, amending and subsequently repealing Council Directives 82/176/EEC, 83/513/EEC, 84/156/EEC, 84/491/EEC,.

(16) Bosma, T. N.; Cottaar, F. H.; Posthumus, M. A.; Teunis, C. J.; van Veldhuizen, A.; Schraa, G.; Zehnder, A. J. Comparison of Reductive Dechlorination of Hexachloro-1,3-butadiene in Rhine Sediment and Model Systems with Hydroxocobalamin. Environ. Sci. Technol. 1994, 28, 1124 1128.

(17) Booker, R. S.; Pavlostathis, S. G. Microbial reductive dechlorination of hexachloro-1,3butadiene in a methanogenic enrichment culture. Water Res. 2000, 34, 4437-4445.

(18) Atlanta, GA: U.S. Department of Health and Human Services, P. H. S. Toxicological profile for Vinyl Chloride.; 2006.

(19) Vogel, T. M.; McCarty, P. L. Biotransformation of tetrachloroethylene to trichloroethylene, dichloroethylene, vinyl chloride, and carbon dioxide under methanogenic conditions. Appl. Environ. Microbiol. 1985, 49, 1080-1083.

(20) Banerjee, S.; Yalkowsky, S. H.; Valvani, S. C.; Valvani, C.; Valvani, S. C. Water Solubility and Octanol / Water Partition Coefficients of Organics . Limitations of the Solubility-Partition 
Coefficient Correlation. Environ. Sci. Technol. 1980, 14, 1227-1229.

(21) Dewulf, J.; Van Langenhove, H.; Everaert, P. Determination of Henry's law coefficients by combination of the equilibrium partitioning in closed systems and solid-phase microextraction techniques. J. Chromatogr. A 1999, 830, 353-363.

(22) Glaze, W. H.; Kang, J.-W.; Chapin, D. H. The Chemistry of Water Treatment Processes Involving Ozone, Hydrogen Peroxide and Ultraviolet Radiation. Ozone Sci. Eng. 1987, 9, 335 352.

(23) von Gunten, U. Ozonation of drinking water: part I. Oxidation kinetics and product formation. Water Res. 2003, 37, 1443-1467.

(24) von Sonntag, C.; von Gunten, U. Chemistry of ozone in water and wastewater treatment: From basic principles to applications; IWA publishing, 2012.

(25) Bolton, J. R.; Stefan, M. I. Fundamental photochemical approach to the concepts of fluence (UV dose) and electrical energy efficiency in photochemical degradation reactions. Res. Chem. Intermed. 2002, 28, 857-870.

(26) Canonica, S.; Meunier, L.; von Gunten, U. Phototransformation of selected pharmaceuticals during UV treatment of drinking water. Water Res. 2008, 42, 121-128.

(27) Lee, M.; Zimmermann-Steffens, S. G.; Arey, J. S.; Fenner, K.; von Gunten, U. Development of Prediction Models for the Reactivity of Organic Compounds with Ozone in Aqueous Solution by Quantum Chemical Calculations: The Role of Delocalized and Localized Molecular Orbitals. Environ. Sci. Technol. 2015, 49, 9925-9935.

(28) Wenk, J.; von Gunten, U.; Canonica, S. Effect of Dissolved Organic Matter on the Transformation of Contaminants Induced by Excited Triplet States and the Hydroxyl Radical. Environ. Sci. Technol. 2011, 45, 1334-1340.

(29) Trucks, G. W.; Schlegel, H. B.; Scuseria, G. E.; Robb, M. A.; Cheeseman, J. R.; Scalmani, G.; Barone, V.; Mennucci, B.; Petersson, G. A.; Nakatsuji, H. Gaussian 09, revision C. 01; Gaussian, Inc. Wallingford, CT 2009.

(30) Tomasi, J.; Mennucci, B.; Cammi, R. Quantum mechanical continuum solvation models. Chem. Rev. 2005, 105, 2999-3093.

(31) E. D. Glendening, A. E. Reed, J. E. Carpenter, F. W. NBO Version 3.1.

(32) Ianni, J. C. Kintecus, Windows Version 5.00, 2014.

(33) Hoigné, J.; Bader, H. Rate constants of reactions of ozone with organic and inorganic compounds in water-I. Non-dissociating organic compounds. Water Res. 1983, 17, 173-183.

(34) Dowideit, P.; von Sonntag, C. Reaction of Ozone with Ethene and Its Methyl- and ChlorineSubstituted Derivatives in Aqueous Solution. Environ. Sci. Technol. 1998, 32, 1112-1119.

(35) Craig, N. C.; Brandon, D. W.; Stone, S. C.; Lafferty, W. J. Partial structure for trans-1,2difluoroethylene from high-resolution infrared spectroscopy. J. Phys. Chem. 1992, 96, 15981605.

(36) Chaudhuri, R. K.; Hammond, J. R.; Freed, K. F.; Chattopadhyay, S.; Mahapatra, U. S. Reappraisal of cis effect in 1,2-dihaloethenes: an improved virtual orbital multireference approach. J. Chem. Phys. 2008, 129, 64101.

(37) Pitzer, K. S.; Hollenberg, J. L. cis- and trans-Dichloroethylenes. The Infrared Spectra from 130-400 Cm. -1 and the Thermodynamic Properties 1. J. Am. Chem. Soc. 1954, 76, $1493-$ 1496.

(38) Getoff, N. Radiation- and photoinduced degradation of pollutants in water. A comparative study. Int. J. Radiat. Appl. Instrumentation. Part C. Radiat. Phys. Chem. 1991, 37, 673-680.

(39) Boue, S.; Srinivasan, R. Differences in reactivity between excited states of cis- and trans-1,3pentadiene. J. Am. Chem. Soc. 1970, 92, 3226-3227.

(40) Srinivasan, R. Kinetics of the Photochemical Dimerization of Olefins to Cyclobutane Derivatives. I. Intramolecular Addition. J. Am. Chem. Soc. 1962, 84, 4141-4145.

(41) Huber, M. M. M.; Canonica, S.; Park, G.-Y.; von Gunten, U. Oxidation of Pharmaceuticals during Ozonation and Advanced Oxidation Processes. Environ. Sci. Technol. 2003, 37, 10161024.

(42) Zimmermann, S. G.; Schmukat, A.; Schulz, M.; Benner, J.; von Gunten, U.; Ternes, T. A. 
Kinetic and Mechanistic Investigations of the Oxidation of Tramadol by Ferrate and Ozone. Environ. Sci. Technol. 2012, 46, 876-884.

(43) Huber, M. M.; Göbel, A.; Joss, A.; Hermann, N.; Löffler, D.; McArdell, C. S.; Ried, A.; Siegrist, H.; Ternes, T. A.; von Gunten, U. Oxidation of Pharmaceuticals during Ozonation of Municipal Wastewater Effluents: A Pilot Study. Environ. Sci. Technol. 2005, 39, 4290-4299.

(44) Jeong, J.; Jung, J.; Cooper, W. J.; Song, W. Degradation mechanisms and kinetic studies for the treatment of X-ray contrast media compounds by advanced oxidation/reduction processes. Water Res. 2010, 44, 4391-4398.

(45) Real, F. J.; Benitez, F. J.; Acero, J. L.; Sagasti, J. J. P.; Casas, F. Kinetics of the Chemical Oxidation of the Pharmaceuticals Primidone, Ketoprofen, and Diatrizoate in Ultrapure and Natural Waters. Ind. Eng. Chem. Res. 2009, 48, 3380-3388.

(46) Swiss Federal Department of the Interior (2000). Ordinance on Contaminants in Food., Bern, Switzerland.

(47) EU. Official Journal of the European Community L 330: Directive 98/83/EG, 1998.

(48) USEPA. National Primary Drinking Water Regulations (NPDWRs). Federal Register, 1989, 54, 27485-27541.

(49) McNeill, K.; Canonica, S. Triplet state dissolved organic matter in aquatic photochemistry: reaction mechanisms, substrate scope, and photophysical properties. Environ. Sci. Process. Impacts 2016, 18, 1381-1399.

(50) Zepp, R. G.; Schlotzhauer, P. F.; Sink, R. M. Photosensitized transformations involving electronic energy transfer in natural waters: role of humic substances. Environ. Sci. Technol. 1985, 19, 74-81.

(51) Acero, J. L.; Haderlein, S. B.; Schmidt, T. C.; Suter, M. J.-F.; von Gunten, U. MTBE Oxidation by Conventional Ozonation and the Combination Ozone/Hydrogen Peroxide: Efficiency of the Processes and Bromate Formation. Environ. Sci. Technol. 2001, 35, 42524259 . 